\begin{tabular}{|c|l|}
\hline Title & Pressure effect on CHF enhancement in pool boiling of nanofluids \\
\hline Author(s) & Sakashita, Hiroto \\
\hline Citation & Journal of nuclear science and technology, 53(6), 797-802 \\
\hline https://doi.org/10.1080/00223131.2015.1072482 \\
\hline Issue Date & 2016-06 \\
\hline Doc URL & http://hdl.handle.net/2115/65859 \\
\hline Rights & $\begin{array}{l}\text { Thisis an Accepted Manuscript of an article published by Taylor \& Francis Group in Journal of nuclear science and } \\
\text { technology on 06/2016, avail able online: http://www.tandfonline.com/doi full/10.1080/00223131.2015.1072482. }\end{array}$ \\
\hline Type & article (author version) \\
\hline File Information & huscap_sakashita.pdf \\
\hline
\end{tabular}

Instructions for use 


\title{
Pressure effect on CHF enhancement in pool boiling of nanofluids
}

\author{
Hiroto Sakashita* \\ Hokkaido University, North 13, West 8, Kita-ku, Sapporo 060-8628, Japan
}

This paper investigates critical heat flux (CHF) in saturated pool boiling for water and $\mathrm{TiO}_{2}$ nanofluid on a $7 \mathrm{~mm}$ diameter vertical copper surface at pressures of 0.1 to $0.8 \mathrm{MPa}$. The nanofluid was prepared by dispersing $0.002 \mathrm{wt} \% \mathrm{TiO}_{2}$ nanoparticles in deionized water. The CHF of the nanofluid was enhanced about two times over that of water boiling at atmospheric pressure. With the increasing pressure, however, the CHF enhancement with the nanofluid decreases, and almost disappears at $0.8 \mathrm{MPa}$.

Key Words; critical heat flux; nanofluids; pool boiling; high pressure; in-vessel retention; experiment

*Corresponding author. E-mail: saka@eng.hokudai.ac.jp 


\section{Introduction}

Nanofluids are suspensions of nanoparticles dispersed in a base liquid. A unique characteristic in nanofluid boiling is that the critical heat flux (CHF) is significantly higher than the CHF of the base liquid, and on account of this characteristic nanofluids have potential applications as coolants of thermal devices with high heat flux components, including nuclear power reactors. The enhancement of the CHF with nanofluids was reported first by You et al. [1] in 2003. They carried out experiments with pool boiling on an upward facing surface with an $\mathrm{Al}_{2} \mathrm{O}_{3}$-water nanofluid at $0.02 \mathrm{MPa}$ and found that the CHF with the nanofluid was 3.1 times higher than that with water. Since then, many researchers [2-6] have measured the CHF in nanofluid boiling using various kinds of nanoparticles $\left(\mathrm{SiO}_{2}, \mathrm{Al}_{2} \mathrm{O}_{3}, \mathrm{CuO}\right.$, and $\left.\mathrm{TiO}_{2}\right)$, and reported that the CHF is markedly enhanced compared with the CHF of water, similarly to the results by You et al.

It has been established that nanoparticles are deposited on heating surfaces during boiling of nanofluids and the general consensus is that this is likely the cause of the CHF enhancement with nanofluids. Kwark et al.[7] measured the CHF of water boiling on a $10 \mathrm{~mm} \times 10 \mathrm{~mm}$ upward facing heating surface on which the $\mathrm{Al}_{2} \mathrm{O}_{3}$ nanoparticles were previously deposited and reported that the CHF of water increases with the improvement in wettability (with the decrease in the static contact angle) due to the nanoparticle deposition. Kim and Kim [8] boiled different nanofluids with $0.2 \mathrm{~mm}$ diameter horizontal wires to deposit layers of the nanoparticles on the wires and concluded that the CHF increase shown by the effect of the nanofluids is a result of both the increase in surface wettability and the capillarity in the porous layer of the deposited nanoparticles. Sakashita [9] measured liquid-vapor behaviors close to a heating surface using a conductance probe during pool boiling of water on an upwards-facing heating surface coated with $\mathrm{TiO}_{2}$ nanoparticles, and specified the macrolayer thicknesses formed 
beneath vapor masses. Sakashita [9] established that the macrolayers formed on the $\mathrm{TiO}_{2}$ coated surface are thicker than those on the uncoated (clean) surface, and concluded that this is most likely a main cause of the CHF enhancement with nanofluids. Kim et al. [10] measured the CHF of water boiling on a $0.2 \mathrm{~mm}$ horizontal wire on which a $\mathrm{TiO}_{2}$ nanoparticle coated layer was previously deposited by previous boiling in nanofluid. The wettability and thickness of the deposited layer were varied by controlling the heat flux and duration of this previous boiling. Through these measurements, Kim et al. concluded that capillarity and additional liquid held in the porous layer (which leads to an increase in the effective macrolayer thickness) are responsible to the CHF increase. In a similar study, Park et al. [11] measured the CHF of water on a $0.49 \mathrm{~mm}$ diameter horizontal wire on which $\mathrm{Al}_{2} \mathrm{O}_{3}$ nanoparticle layers with different thicknesses and porosities were previously deposited by previous boiling in the nanofluid. Park et al observed that with the increase in the previous boiling time the CHF increases steeply for short previous boiling times, and after peaking gradually decreases with longer previous boiling times. Park et al. mentioned that the steep increase in the CHF at short previous boiling times can be explained by the increase in wettability and the change in hydrodynamic instability, and that the gradual decrease in the CHF for longer previous boiling times by a decrease in the porosity of the nanoparticle layer.

As mentioned above, valuable information has been accumulated for the CHF enhancement with nanofluids; however, most studies are carried out at atmospheric or lower pressures. Considering the application of nanofluids in emergency core cooling systems in nuclear power plants, it is important to know the CHF behavior of nanofluids at higher pressures. For example, Buongiorno et al. [12] proposed the use of nanofluids to enhance the in-vessel retention (IVR) capability in management strategies of severe accidents in light-water reactors. In the IVR strategy, the reactor vessel is flooded with water if a severe accident occurs and the decay heat of the molten core relocated to the 
lower head of the reactor vessel is removed through nucleate boiling on the outer wall of the reactor vessel. Therefore, if the CHF of the water can be expected to be enhanced by using nanofluids in a severe accident condition, the use of nanofluids would improve the IVR safety margin of currently operating reactors and enable the IVR strategy to be applied to advanced reactors with higher core power densities. Under severe accident conditions, it is expected that the ambient pressure surrounding the reactor vessel would be higher than the atmospheric pressure, and therefore it is important to examine the CHF behavior of nanofluids at higher than atmospheric pressure to assess the capability and applicability of the IVR strategy.

In research on the CHF of nanofluids at pressures above the atmospheric pressure, Lee et al. [13] carried out experiments with $\mathrm{Fe}_{3} \mathrm{O}_{4}$-water and $\mathrm{Al}_{2} \mathrm{O}_{3}$-water nanofluids boiling on $0.4 \mathrm{~mm}$ diameter horizontal wires at pressures of $0.1,0.6$, and 1.0 $\mathrm{MPa}$, and reported that the CHF enhancement remains at almost the same value (1.4 to 1.6 times the CHF of water) at the three different pressures. However, it is also well known that the CHF of fine wires varies in a complicated manner dependent on the wire diameter $[14,15]$. Therefore, there is the possibility that the effect of pressure on the CHF enhancement using nanofluids will be different for different configurations of the boiling surfaces. Kwark et al. [7] carried out an experiment with water boiling on a 10 $\mathrm{mm} \times 10 \mathrm{~mm}$ surface with an $\mathrm{Al}_{2} \mathrm{O}_{3}$ nanoparticle coated layer previously deposited by nucleate boiling of an $\mathrm{Al}_{2} \mathrm{O}_{3}$-water/ethanol nanofluid. They measured the $\mathrm{CHF}$ at pressures of $0.02,0.05,0.1$ and $0.2 \mathrm{MPa}$, and obtained results where the CHF enhancement due to the nanoparticle coating gradually decreases as the pressure increases. To the best of the author's knowledge, no other research has been reported for the CHF in boiling with nanofluids at higher pressures.

This study carried out an experiment with boiling of $\mathrm{TiO}_{2}$-water nanofluid on a 7 mm diameter copper heating surface. The heating surface was placed vertically to allow 
the observation of the boiling behaviors on the heating surface using high speed video under high pressure condition. The CHF in water and with the nanofluid was measured at pressures 0.1 to $0.8 \mathrm{MPa}$, and the effect of the pressures on the CHF enhancement using nanofluids was examined.

\section{Experiment}

The experiments were carried out in saturated pool boiling conditions. Figure 1 shows the heating module used in the present experiments. One end of a copper rod placed in a cylindrical stainless steel housing unit served as the heating surface and it was heated with a cartridge heater inserted into the copper rod. The diameter of the heating surface was $7 \mathrm{~mm}$. Three sheathed thermocouples (0.5 $\mathrm{mm}$ diameter) were embedded $5 \mathrm{~mm}, 12 \mathrm{~mm}$, and $19 \mathrm{~mm}$ below the heating surface to determine the surface temperature and surface heat flux. The copper rod and the surrounding $1 \mathrm{~mm}$ thick stainless steel flange (the end surface of the housing unit) were attached by shrink-fitting. The surfaces of the copper and the stainless steel flange were machined to be flush, and then $\mathrm{Ni}$ was electroplated over the two surfaces to avoid corrosion and nucleation of bubbles at the interface between the copper surface and the surrounding flange. The thickness of the Ni plating was about $3 \mu \mathrm{m}$. Figure 2 shows the high pressure cell. The cell is cylindrical with an inner diameter of $50 \mathrm{~mm}$ and a height of $150 \mathrm{~mm}$. The heating module shown in Figure1 was inserted in the cell from the side of the cell, and a sapphire window was provided in the opposite side of the cell. The boiling behaviors on the vertical heating surface were observed via the sapphire window using high speed video with a maximum 2000 fps and a microscope with a maximum 320-fold magnification.

$<$ Figure 1 $>$

$<$ Figure 2> 
The present experiment used $\mathrm{TiO}_{2}$ nanoparticles (Sigma-Aldrich) with a vendor specified average size of $25 \mathrm{~nm}$. The experiments with the nanofluid were carried out in the following manner: $0.002 \mathrm{wt} \%$ of $\mathrm{TiO}_{2}$ nanoparticles was mixed with de-ionized water (electro conductivity below $0.2 \mu \mathrm{S} \mathrm{cm}{ }^{-1}$ ) and dispersed in an ultrasonic bath for $30 \mathrm{~min}$. Then the nanofluid was poured into the high pressure cell and decompressed with a vacuum pump to make it boil at room temperature. After boiling at room temperature for several minutes for degassing, the liquid was heated to a saturation temperature at a set pressure level by heaters wound around the high pressure cell and maintained at that temperature by adjusting the input to the heaters and the flow rate of the cooling water through the cooling coils. Then the boiling curves were recorded at stepwise increasing heat inputs to the cartridge heater in the copper heating module. When approaching the CHF, the size of the increments in the heat input was reduced, and the heat flux when the surface temperature was raised rapidly was defined as the CHF. The time from the start of boiling to the occurrence of CHF was about 1 to 1.5 hrs.

During each experiment, the bulk temperature of the liquid was maintained within $\pm 0.5 \mathrm{~K}$ of the set saturation temperature. The uncertainties in the saturation pressure caused by this temperature uncertainty increased with the saturation pressure and were estimated as $\pm 0.01 \mathrm{MPa}$ at $0.8 \mathrm{MPa}$, the maximum pressure in the present experiment. The surface temperature and the surface heat flux were calculated from the three thermocouples embedded in the copper rod by assuming steady state one-dimensional heat conduction. Figure 3 shows examples of temperature distributions at three different heat fluxes for the nanofluid boiling at $0.5 \mathrm{MPa}$. The heat flux of $q=4.56 \mathrm{MW} \mathrm{m}^{-2}$ is about $1 \%$ lower than the CHF. As shown in Figure 3, the linearity of temperatures at the three locations is quite good and the deviation from the linearity was less than $1 \%$. The heat loss by the heat conduction trough the surrounding stainless steel flange was estimated by solving the 2-D heat conduction equation and the error due to 
the heat loss was determined as less than $4 \%$ of the heat flux estimated with the three thermocouples.

$<$ Figure $3>$

\section{Experimental Results}

\subsection{Appearances of Water Boiling at Higher Pressures and of Heating Surface after the CHF Measurements with Nanofluid}

Figure 4 shows the appearance of boiling for water at $0.8 \mathrm{MPa}$, the highest pressure in the present experiments. Figure 4(a) shows the boiling appearance at $q=1.1$ $\mathrm{MW} \mathrm{m}^{-2}\left(q / q_{C H F}=0.24\right)$ and Figure $4(\mathrm{~b})$ is at $q=3.3 \mathrm{MW} \mathrm{m}^{-2}\left(q / q_{C H F}=0.73\right)$, with the $7 \mathrm{~mm}$ diameter heating surface encircled by a broken line. At atmospheric pressure, large coalesced bubbles completely covering the heating surface are formed at heat fluxes above around $0.5 \mathrm{MW} \mathrm{m}^{-2}$ (images are not shown). At higher pressures, the bubble growth rates and the diameters at detachment of the bubbles decrease with the increase in the pressure, and a large vapor mass completely covering the heating surface is not formed at $q=1.1 \mathrm{MW} \mathrm{m}^{-2}$, but there are several smaller coalesced bubbles on the heating surface (Figure 4(a)). At $q=3.3 \mathrm{MW} \mathrm{m}^{-2}$, a large coalesced bubble completely covers the heating surface (Figure 4(b)). In the present experiments with a $7 \mathrm{~mm}$ diameter heating surface, the large coalesced bubbles completely covering the heating surface were formed at $40 \%$ to $50 \%$ of the CHF.

$<$ Figure 4>

Figure 5 shows the appearances of the heating surface after the CHF measurements for the boiling of the nanofluid at three different pressures: $0.1,0.25$, and 0.8 MPa. The appearances of the $\mathrm{TiO}_{2}$ coatings appear somewhat different on the three surfaces probably due to the differences in shape and size of the bubbles and the nucleation site densities, while most of the surface is covered with a $\mathrm{TiO}_{2}$ layer. For the 
three surfaces, the static contact angle was measured at room temperature under atmospheric pressure by detaching the heating module from the high pressure cell and by placing a water droplet ( $3 \mu \mathrm{L})$ on the surface. The static contact angles at the three surfaces showed similar values, around $0^{\circ}$ to $5^{\circ}$.

$<$ Figure 5 $>$

\subsection{Pressure Effect on CHF Enhancement with the Nanofluid}

Figure 6 shows boiling curves for water and the nanofluid at two pressures, 0.1 and 0.6 MPa, with the arrows in the figures indicating the CHF. Figure 6 also shows the predicted results for water with the Stephan and Abdelsalam [16] correlation. In the pressure range of the present experiment, there are no obvious differences in the heat transfer coefficients of water and the nanofluid, and the boiling curves agree fairly well with the results with the Stephan and Abdelsalam correlation. However, the enhancement ratios of the CHF with the nanofluid are quite different for 0.1 and $0.6 \mathrm{MPa}$.

$<$ Figure 6>

Figure 7 shows the variation in the measured CHF with pressure for water and the nanofluid. The CHF of the boiling nanofluid is larger than that of water over the whole range of pressures, showing that the CHF of water is enhanced with the $\mathrm{TiO}_{2}$ nanofluid. However, the CHF values of water and nanofluid to approach similar values with the increases in pressure.

Figure 7 also plots the predicted results with the widely used CHF correlation in Equation (1) proposed by Zuber [17] and Lienhard and Dhir [18], and the correlation proposed by Kandlikar [19]. The correlation by Zuber and Lienhard and Dhir is given by

$$
q_{C H F}=K \cdot \rho_{v}{ }^{1 / 2} H_{f g}\left\{\sigma g\left(\rho_{l}-\rho_{v}\right)\right\}^{1 / 4}
$$


where $K$ is a constant which Zuber derived theoretically as $K=0.131$, and Lienhard and Dhir modified to $K=0.149$. Kandlikar proposed a CHF model incorporating the effects of a dynamic receding contact angle and surface orientation as given by

$$
q_{C H F}=\rho_{v}{ }^{1 / 2} H_{f g}\left\{\sigma g\left(\rho_{l}-\rho_{v}\right)\right\}^{1 / 4} \cdot\left(\frac{1+\cos \beta}{16}\right)\left[\frac{2}{\pi}+\frac{\pi}{4}(1+\cos \beta) \cos \phi\right]^{\frac{1}{2}}
$$

where $\beta$ is the dynamic receding contact angle and $\phi$ is the angle of inclination of the surface measured in relation to the upward position $\left(\phi=90^{\circ}\right.$ for the present measurements with the vertical surface). The present experiments did not measure the dynamic receding contact angle, $\beta$, and therefore, $\beta=45^{\circ}$, the value recommended for water/copper systems by Kandlikar, was used for water. For the nanofluid, $\beta$ was assumed to be $0^{\circ}$, because the static contact angle measured after the CHF measurements was close to $0^{\circ}$ as mentioned in the preceding section.

For water boiling, the measured $\mathrm{CHF}$ at $0.1 \mathrm{MPa}$ agrees well with the values predicted by Equation (1), at higher pressures however, the measured CHF values are larger than the predicted values and the discrepancy increases with the increases in pressure. Equation (2) predicts lower values than the present data for water and nanofluid and the predicted values by Equation (1) over the whole range of pressures (The main reason of the discrepancy for the CHF of water between Equations (1) and (2) comes from the term in the last parenthesis on the right hand side of Equation (2) expressing the effect of the surface orientation. With $\beta=45^{\circ}$, Equation (2) predicts the CHF for a vertical surface $\left(\phi=90^{\circ}\right)$ as $43 \%$ lower than the CHF for a horizontal surface $\left.\left(\phi=0^{\circ}\right)\right)$.

The reason why the present data of CHF for water tends to be different from the predictions of Equation (1) with the increase in pressure is unclear. The present data are obtained for a vertical surface of relatively small size ( $7 \mathrm{~mm}$ diameter), and this may lead to a pressure dependence different from Equation (1) derived for an infinitely large upward facing surface. Further study would be necessary to elucidate details of this. 
Figure 8 plots the CHF enhancement ratio versus pressure (averaged CHF values of two or three data sets were used for water at $0.1,0.5$ and $0.6 \mathrm{MPa}$.) The CHF of the nanofluid is about double the CHF of water at $0.1 \mathrm{MPa}$, but the enhancement ratio decreases with increasing pressure falling to 1.08 at $0.8 \mathrm{MPa}$. These results show that the effect of the CHF enhancement with nanofluid deteriorates with the increase in pressure and almost disappears at $0.8 \mathrm{MPa}$.

$<$ Figure $7>$

$<$ Figure $8>$

The CHF enhancement mechanism observed with nanofluids has not been clarified; however, according to previous studies at atmospheric or lower pressures, the improved surface wettability due to the deposition of nanoparticles on the heating surfaces is likely to be one of the main causes of the CHF enhancement. In the following, the results of Figure 8 are examined from the viewpoint of surface wettability under high pressure (high temperature) conditions. The research into wettability at high temperature conditions has been carried out by Bernardin et al. [20] and Hazuku et al. [21]. Bernardin et al. measured the contact angles of water droplets on an aluminum plate in the temperature range of 25 to $175{ }^{\circ} \mathrm{C}$ (pressure range 0.1 to $0.82 \mathrm{MPa}$ ), and obtained the result that the contact angle, $\theta$, remains at a constant value for surface temperatures below $120{ }^{\circ} \mathrm{C}$, and that above $120{ }^{\circ} \mathrm{C}$ it decreases in a linear manner with the temperature derivative $d \theta / d T=-0.55 \mathrm{deg} \cdot \mathrm{K}^{-1}$. Hazuku et al. measured the contact angles of water droplets on aluminium and stainless steel surfaces at surface temperature up to $300{ }^{\circ} \mathrm{C}$ (15 MPa) and obtained results similar to Bernardin et al. for surface temperatures below $200{ }^{\circ} \mathrm{C}$. The surface wettability of water boiling in the present experimental conditions was estimated based on the results by Bernardin et al. and shown in Figure 9. Figure 9 plots the changes in the contact angle of water with pressure, under the assumption that the contact angle remains constant to $120{ }^{\circ} \mathrm{C}$ (the measured value at 
room temperature, $75^{\circ}$, was used), and that it decreases with the gradient $d \theta / d T=-0.55 \mathrm{deg} \cdot K^{-1}$ above $120{ }^{\circ} \mathrm{C}$. In Figure 9, the solid symbols $(\bullet)$ are for the contact angle based on the saturation temperature at each pressure, and the open symbols (O) are based on the measured surface temperature at the CHF. It is found that the contact angles at the CHF (the open symbols (O)) decrease greatly as the pressure increases from 0.1 to 0.4 MPa. From the result in Figure 9, it may be surmised that a main reason why the CHF enhancement effect decreases with the increasing pressure could be that the surface wettability is increased with the increase in pressure, and that the effect of the wettability improvement due to the nanoparticle deposition on the CHF is reduced.

$<$ Figure 9 $>$

\section{Conclusions}

The CHF for pool boiling of water and $\mathrm{TiO}_{2}$-water nanofluid on a $7 \mathrm{~mm}$ diameter vertical copper surface was measured in the pressure range of 0.1 to $0.8 \mathrm{MPa}$. The conclusions obtained in the present study may be summarized as follows:

(1) The CHF of water and nanofluid increase steeply with the increase in the pressure.

(2) The effect of the CHF enhancement with the nanofluid decreases with the increase in the pressure and almost disappears at $0.8 \mathrm{MPa}$.

(3) When the CHF enhancement is assumed to be caused by the improvement in surface wettability due to the deposition of nanoparticles on the heating surface, the cause of the result described in (2) may be that the wettability of the heating surface is increased with the increase in pressure. 


\section{Nomenclature}

C Specific heat $\left[\mathrm{J} \mathrm{kg}^{-1} \mathrm{~K}^{-1}\right]$

$g \quad$ Gravitational acceleration $\left[\mathrm{m} \mathrm{s}^{-2}\right]$

$H_{f g} \quad$ Latent heat of evaporation $\left[\mathrm{J} \mathrm{kg}^{-1}\right]$

K Constant in Equation (1)

$p \quad$ Pressure $[\mathrm{Pa}]$

$q \quad$ Heat flux $\left[\mathrm{W} \mathrm{m}^{-2}\right]$

$T$ Temperature $\left[{ }^{\circ} \mathrm{C}\right]$

\section{Greek symbols}

$\beta \quad$ Dynamic receding contact angle

$\Delta T_{\text {sat }}$ Superheat [K]

$\rho \quad$ Density $\left[\mathrm{kg} \mathrm{m}^{-3}\right]$

$\sigma \quad$ Surface tension $\left[\mathrm{N} \mathrm{m}^{-1}\right]$

$\theta \quad$ Contact angle [degree]

$\phi \quad$ Angle of inclination of the surface measured relative to the upward position $\left[{ }^{\circ}\right]$

\section{Subscripts}

CHF Critical heat flux

l Liquid

$v \quad$ Vapour

w Wall 


\section{References}

[1] You SM, Kim JH, Kim KH. Effect of nanoparticles on critical heat flux of water in pool boiling heat transfer. Appl. Phys. Lett. 2003; 83-16: 3374-3376.

[2] Vassallo P, Kumar R, D’Amico S. Pool boiling heat transfer experiments in silica-water nano-fluids. Int. J. Heat Mass Transfer.2004; 47: 407-411.

[3] Milanova D, Kumar R. Role of ions in pool boiling heat transfer of pure and silica nanofluids. Appl. Phys. Lett. 2005; 87: 233107.

[4] Bang IC, Chang SH. Boiling heat transfer performance and phenomena of $\mathrm{Al}_{2} \mathrm{O}_{3}$-water nanofluids from a plain surface in a pool. Int. J. Heat Mass Transfer. 2005; 48: 2407-2419.

[5] Kim H, Kim J, Kim MH. Effect of nanoparticles on CHF enhancement in pool boiling of nanofluids. Int. J. Heat Mass Transfer. 2006; 49: 5070-5074.

[6] Liu ZH, Xiong JG, Bao R. Boiling heat transfer characteristics of nanofluids in a flat heat pipe evaporator with micro-grooved heating surface. Int. J. Multiphase Flow.2007; 33: 1284-1295.

[7] Kwark SM, Moreno G, Kumar R, Moon H, You SM. Nanocoating characterization in pool boiling heat transfer of pure water. Int. J. Heat Mass Transfer. 2010; 53: 4579-4587.

[8] Kim HD, Kim MH. Effect of nanoparticle deposition on capillary wicking that influences the critical heat flux in nanofluids. Appl. Phys. Lett. 2007; 91: 014104.

[9] Sakashita H. CHF and near-wall boiling behaviors in pool boiling of water on a heating surface coated with nanoparticles. Int. J. Heat Mass Transfer. 2012; 55: 7312-7320.

[10]Kim H, Kim E, Kim MH. Effect of nanoparticle deposit layer porosities on pool boiling critical heat flux of water from a thin wire. Int. J. Heat Mass Transfer. 2014; 69: 164-172.

[11] Park SD, Moon SB, Bang IC, Effects of thickness of boiling-induced nanoparticle deposition on the saturation of critical heat flux enhancement. Int. J. Heat Mass Transfer. 2014; 78: 506-514. 
[12] Buongiorno J, Hu LW, Apostolakis G, Hannink R, Lucas T, Chupin AA. Feasibility assessment of the use of nanofluids to enhance the in-vessel retention capability in light-water reactors. Nucl. Eng. Des. 2009; 239: 941-948.

[13] Lee JH, Lee T, Jeong YH. The effect of pressure on the critical heat flux in water-based nanofluids containing $\mathrm{Al}_{2} \mathrm{O}_{3}$ and $\mathrm{Fe}_{2} \mathrm{O}_{3}$ nanoparticles. Int. J. Heat Mass Transfer. 2013; 61: 432-438.

[14] Lienhard LH, Watanabe K. On correlating the peak and minimum boiling heat fluxes with pressure and heater configuration. J. Heat Transfer. 1966; 88: 94-100.

[15] Sun KH, Lienhard JH. The peak pool boiling heat flux on horizontal cylinders. Int. J. Heat Mass Transfer.1970; 13: 1425-1439.

[16] Stephan K, Abdelsalam M. Heat-transfer correlations for natural convection boiling. Int. J. Heat Mass Transfer. 1980; 20: 73-87.

[17] Zuber N. On the stability of boiling heat transfer. J. Heat Transfer.1958; 80: 711-720.

[18] Lienhard JK, Dhir VK. Hydrodynamic prediction of peak pool boiling. J. Heat Transfer. 1973; 95: 152-158.

[19] Kandlikar SG. A theoretical model to predict pool boiling CHF incorporating effects of contact angle and orientation. J. Heat Transfer; 2001; 123:1071-1079.

[20] Bernardin JD, Mudawar I, Walsh CB, Frances EI. Contact angle temperature dependence for water droplets on practical aluminium surfaces. Int. J. Heat Mass Transfer. 1997; 40: 1017-1033.

[21] Hazuku T, Hirose Y, Hayashi T, Pollman AG, Fukuhara Y, Takamasa T. [Effect of radiation on surface wettability under high-temperature and high-pressure environment]. Nihon-Kikaigakkai-Ronbunshu B-hen (Transactions of Japan Society of Mechanical Engineers, Series B). 2009; 75-758: 1911-1916 [in Japanese]. 


\section{Captions of figures}

Figure 1 Heating module.

Figure 2 High pressure cell.

Figure 3 Temperature distributions in the copper heating module (with boiling nanofluid at $0.5 \mathrm{MPa})$.

Figure 4 Appearance of water boiling at $0.8 \mathrm{MPa}$ at two heat fluxes.

Figure 5 Appearance of the heating surface after the CHF measurements with the nanofluid at three pressures.

Figure 6 Boiling curves for water and nanofluid at 0.1 and 0.6 MPa.

Figure 7 CHF vs. pressure for water and nanofluid.

Figure 8 CHF enhancement ratio vs. pressure.

Figure 9 Change in contact angle with pressure, estimated from the results by Bernardin et al. 


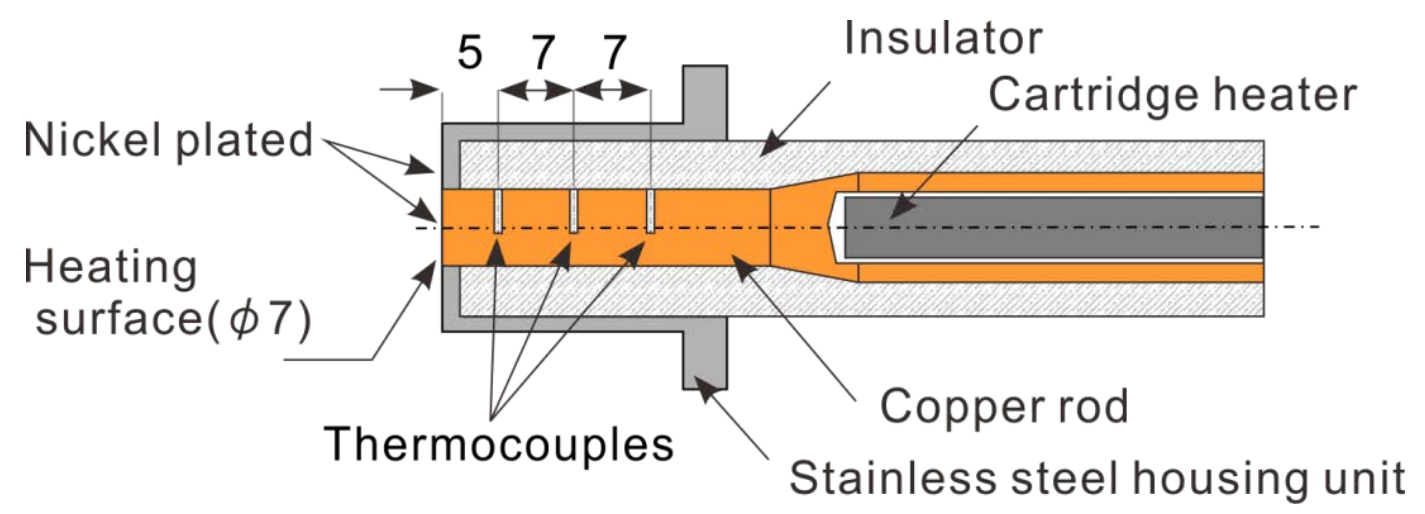

Figure 1 Heating module

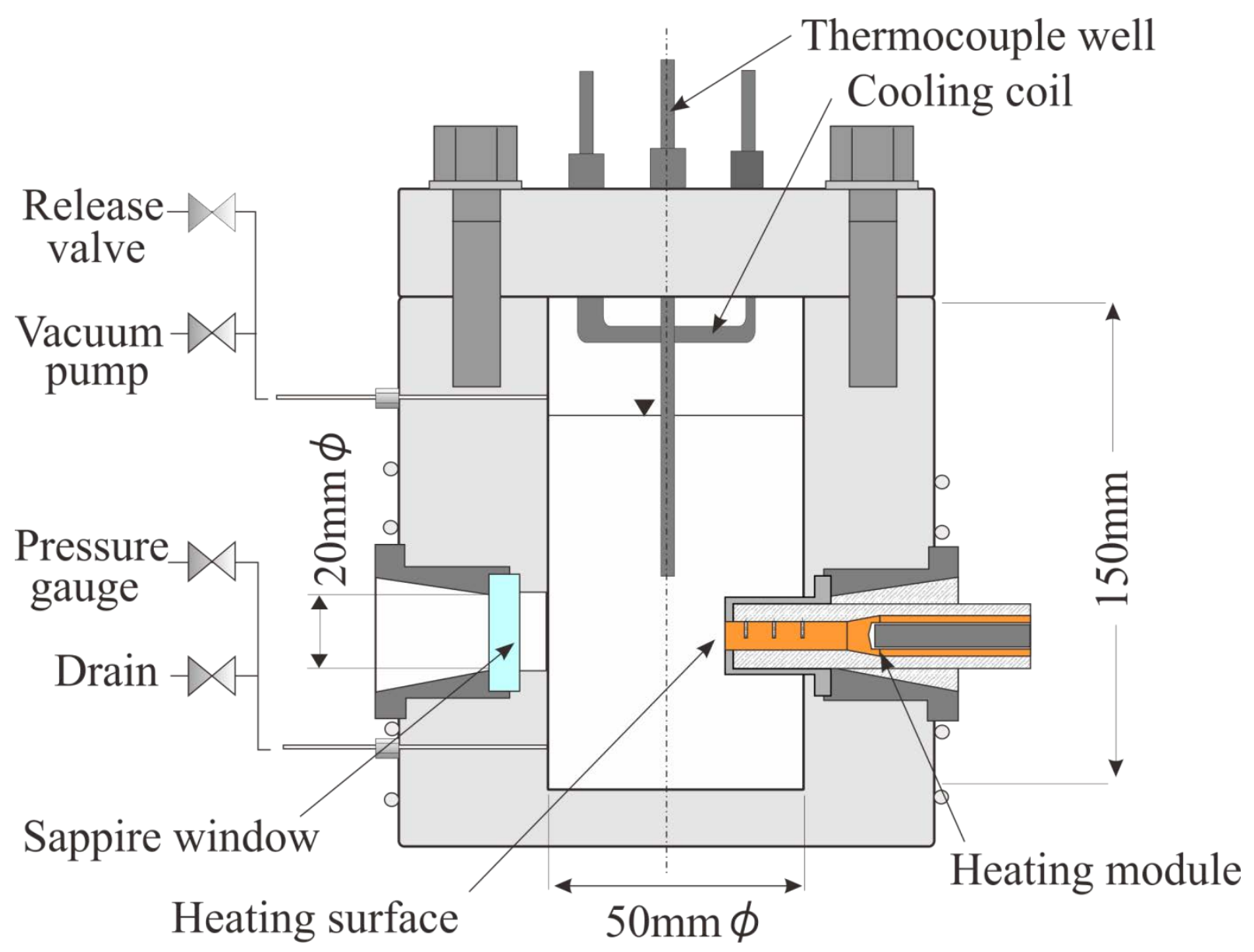

Figure 2 High pressure cell 


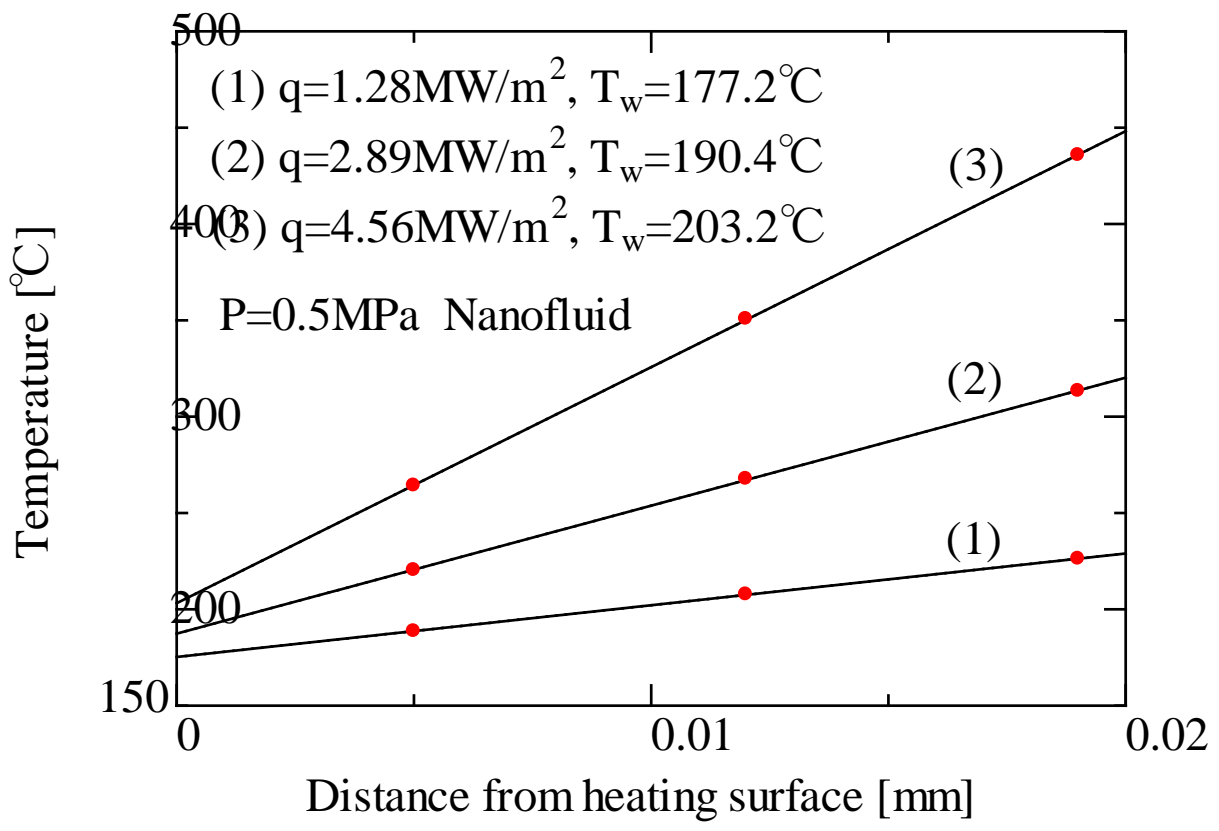

Figure 3 Temperature distributions in the copper heating module (with boiling nanofluid at $0.5 \mathrm{MPa}$ ) 


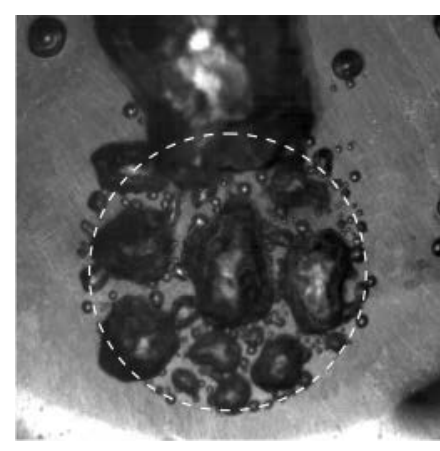

(a) $\mathrm{q}=1.1 \mathrm{MW} / \mathrm{m}^{2}$

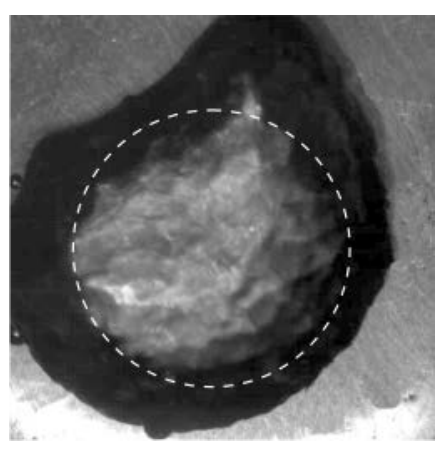

(b) $\mathrm{q}=3.3 \mathrm{MW} / \mathrm{m}^{2}$

Figure 4 Appearance of water boiling at $0.8 \mathrm{MPa}$ at two heat fluxes

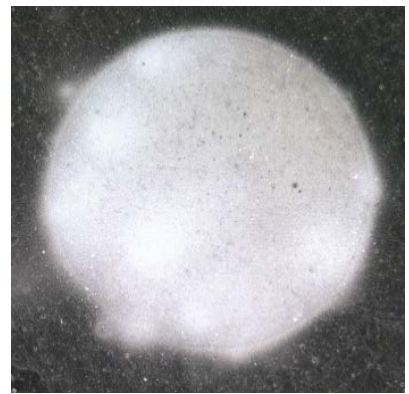

(a) $0.1 \mathrm{MPa}$

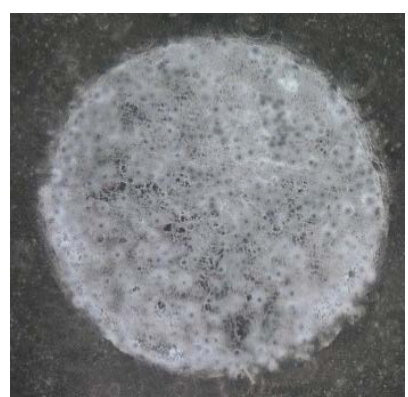

(b) $0.25 \mathrm{MPa}$

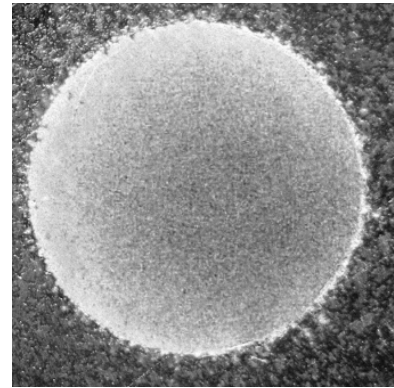

(c) $0.8 \mathrm{MPa}$

Figure 5 Appearance of the heating surface after the CHF measurements with the nanofluid at three pressures 


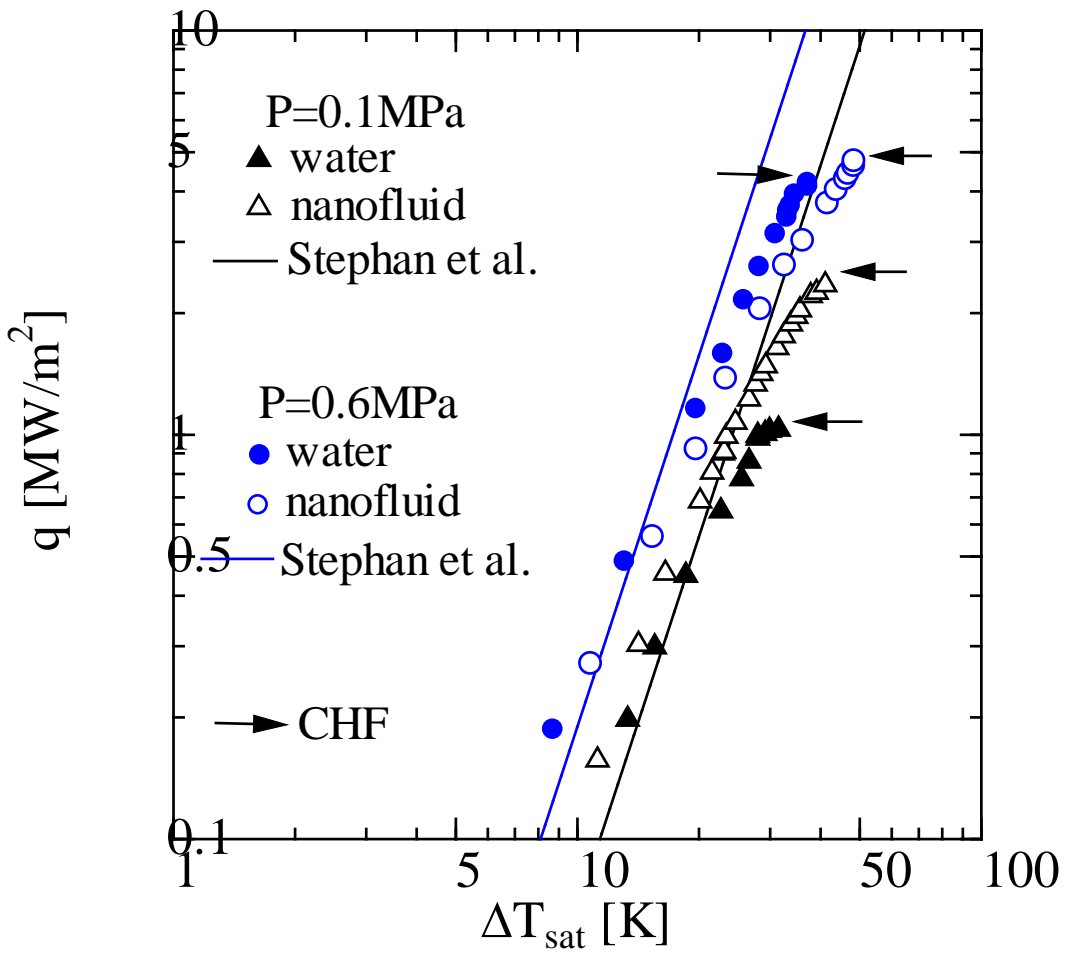

Figure 6 Boiling curves for water and nanofluid at 0.1 and $0.6 \mathrm{MPa}$ 


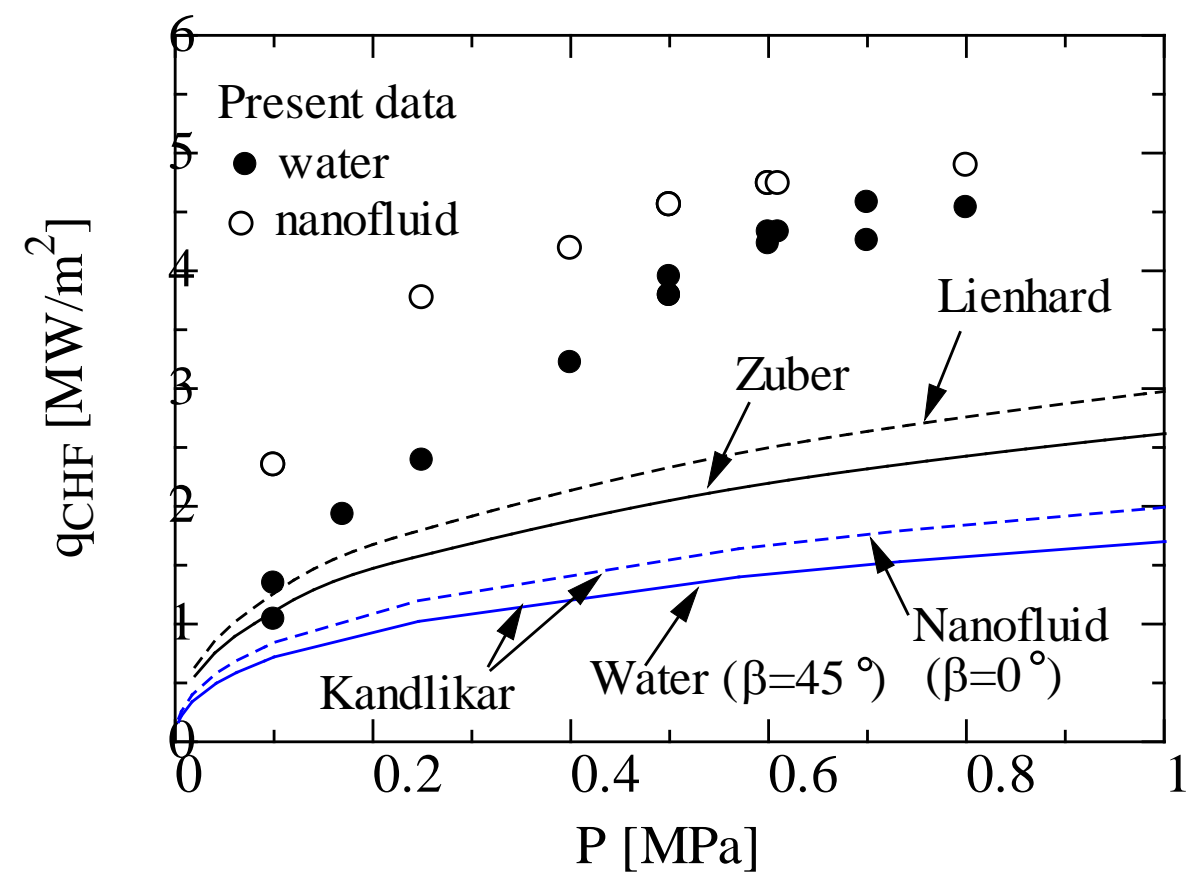

Figure 7 CHF vs. pressure for water and nanofluid

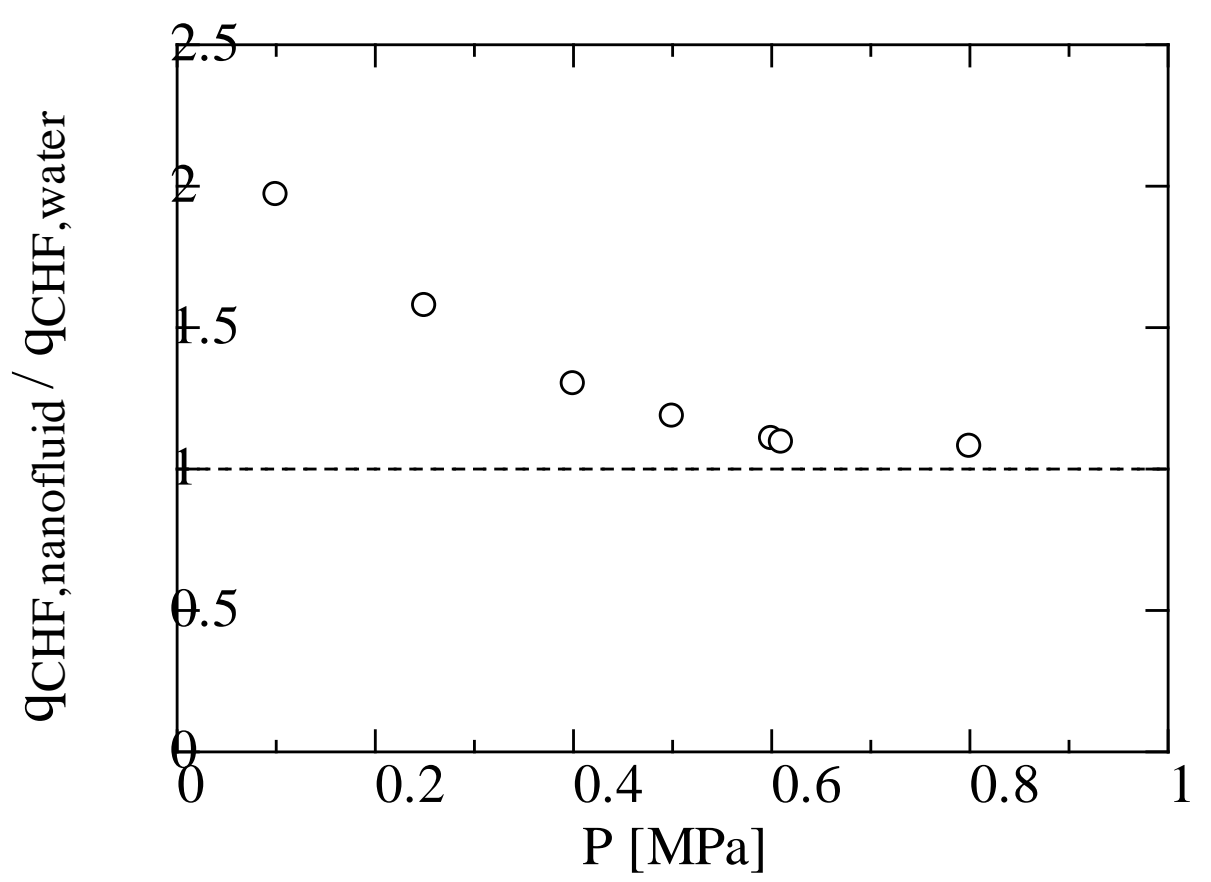

Figure 8 CHF enhancement ratio vs. pressure 


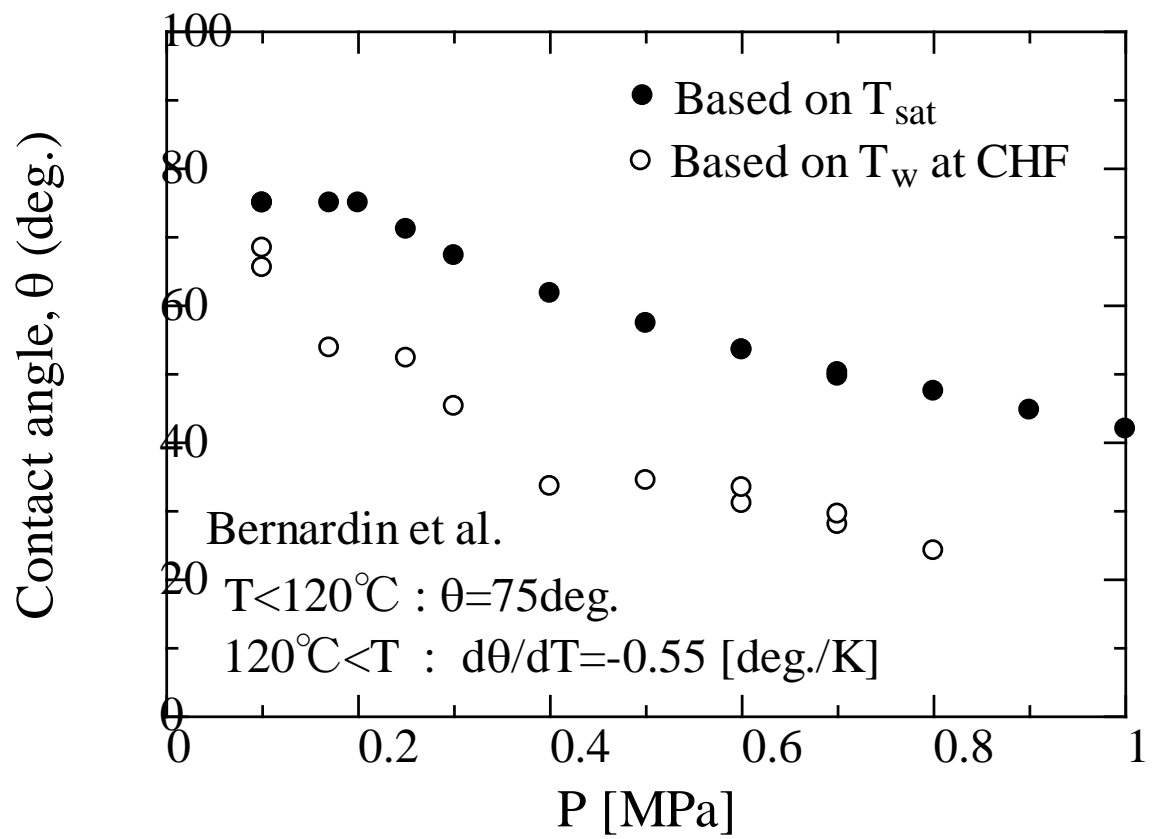

Figure 9 Change in contact angle with pressure, estimated from the results by Bernardin et al. 